\title{
Os procedimentos adotados pelos Tribunais de Contas da Bahia para a verificação das receitas e despesas vinculadas à educação *
}

- Nicholas Davies **

\section{Resumo}

0 artigo examinou, com base em resoluções e/ou relatórios de contas, os procedimentos adotados pelos Tribunais de Contas do Estado (TCE) e dos Municípios (TCM) da Bahia para a verificação da receita e despesa vinculada à educação e constatou uma série de omissões, inconsistências e equívocos que muito provavelmente reduziram o montante de recursos legalmente vinculados à educação. 0 TCE, por exemplo, se limitou à contabilização do percentual mínimo dos impostos e nunca mencionou as receitas adicionais a este mínimo, como o salário-educação, os repasses federais para merenda e outros programas ou operações de crédito vinculadas à educação, significativas no caso da Bahia. Além disso, os relatórios contêm dados discrepantes e confundem gastos na função orçamentária Educação com os realizados em manutenção e desenvolvimento do ensino, dois conceitos diferentes. Também o TCM cometeu muitos equívocos, em suas resoluções, a começar pela terminologia. Empregou 'ensino básico' no lugar de 'educação infantil' e confundiu despesas no ensino (categoria mais ampla) com despesas no Fundef (categoria mais restrita). Incorreu em ilegalidade ao aceitar que parte dos $40 \%$ dos recursos do Fundef (ou do Fundeb) fossem destinados a escolas comunitárias, confessionais ou filantrópicas.

Palavras-chave: Financiamento da educação. Orçamento da educação. Tribunais de Contas da Bahia.

\section{The procedures adopted by the Audit Courts of Bahia for checking revenue and expenses linked to education Abstract}

The article examined, on the basis of resolutions and/or reports, the procedures adopted by the Audit Offices of the State (TCE) and Municipalities (TCM) of

\footnotetext{
Este artigo é resultado de pesquisa apoiada pelo CNPq através de bolsa de produtividade em pesquisa desde março de 2007.

". Doutor em Educação, USP; Professor da Universidade Federal Fluminense (UFF). E-mail: nicholas@pq.cnpq.br
} 
Bahia, to check the revenue and expenditure linked to education and found a number of omissions, inconsistencies and mistakes which most likely have reduced the amount of funds earmarked to education. The State Audit Office, for example, has only taken into account the $25 \%$ minimum percentage of taxes (as provided in the Brazilian Federal Constitution) and never mentioned extra revenue to this minimum, such as payroll-linked contribution, federal transfers for programmes such as school meals or credit operations linked to education. In addition, the reports contain inconsistent data and confuse two different concepts, that of expenditure on the budgetary notion of education with the concept of maintenance and development of education. The Audit Office of the Municipalities has also made a number of mistakes in its resolutions. It employed the term 'basic education' (a much broader term) instead of 'education for children prior to 6 years old' and confused expenses on education (a broader term) with expenses on Fundef (a more restricted category, as it refers to part of the expenses on education). Furthermore, it adopted an illegal interpretation by accepting that part of $40 \%$ of Fundef (or Fundeb) public funds be used by non-public so-called community, religious or charity schools.

Keywords: Education funding. Education budget. The Audit Offices of the Brazilian State of Bahia

\section{Los procedimientos adoptados por los} Tribunales de Cuentas del estado brasileño de Bahia para la verificación de ingresos $y$ despesas vinculadas a la educación Resumen

El artículo ha examinado, con base en resoluciones y/o informes de cuentas, los procedimientos adoptados por los Tribunales de Cuentas de la Provincia (TCE) y de los Municipios (TCM) de Bahia para la verificación de los ingresos e despesas vinculadas a educación y ha constatado una serie de omisiones, inconsistencias y equívocos que muy probablemente han reducido el montante de fondos legalmente vinculados a la educación. EI TCE, por ejemplo, ha limitado a la contabilización del porcentual mínimo de los impuestos y nunca mencionó los ingresos adicionales a este mínimo, como las transferencias federales para el gobierno provincial y otros programas u operaciones de crédito vinculadas a la educación, significativas en Bahia. Adicionalmente, los informes contienen dados discrepantes y confunden gastos en la función presupuestaria Educación con los realizados en manutención y desarrollo de enseñanza, dos conceptos diferentes. También el TCM ha cometido muchos equívocos en sus resoluciones, a empezar por la terminología. 
Ha utilizado 'ensino básico' en el lugar de 'educación infantil' y confundido despesas en la enseñanza (una categoría más amplia) con despesas en Fundef (una categoría más restricta). Ha cometido una ilegalidad al aceptar que parte de los 40\% delos fondos de Fundef (o Fundeb) fuesen destinados a escuelas comunitarias, confesionales o filantrópicas.

Palabras clave: Financiamiento de la educación. Presupuesto de la educación. Tribunales de Cuentas de Bahia

\section{Introdução}

Este artigo examina os procedimentos adotados pelos Tribunais de Contas do Estado e dos Municípios da Bahia na verificação da aplicação dos recursos vinculados à educação, sendo parte de uma pesquisa sobre o papel dos Tribunais de Contas (TCs) do Brasil nesta verificação. Foi suscitada inicialmente pela experiência do autor na análise da aplicação da verba da educação por governos estadual e municipais do Rio de Janeiro e na sua fiscalização por parte do TC do Estado do Rio de Janeiro (DAVIES, 1999, 2000). Posteriormente, examinamos os procedimentos adotados por quase todos os TCs (DAVIES, $2001 b$ ) e constatamos diferenças significativas entre eles sobre o que consideravam receitas e despesas vinculadas à Manutenção e Desenvolvimento do Ensino (MDE), nem sempre coincidentes com o que parece estar na letra e espírito da legislação pertinente: a Lei Federal nº 7.348 (BRASIL, 1985), a Constituição Federal de 1988 (BRASIL, 1988), a Lei de Diretrizes e Bases da Educação Nacional (LDB) (BRASIL, 1996b), as Emendas Constitucionais (EC) $n^{\circ} .14$ (BRASIL, 1996a), e $n^{\circ} .53$ (BRASIL, 2006). A experiência de Cesar Callegari (1997) na análise das contas do governo estadual de São Paulo também confirma a importância do conhecimento sobre tais interpretações, que, materializadas em instruções normativas, resoluções ou deliberações, são na prática mais importantes do que o estipulado na LDB (BRASIL, 1996b), pois os governos estaduais e municipais procuram seguir (quando o fazem, é claro!) as orientações dos TCs na sua prestação de contas, e não necessariamente as disposições da LDB ou de pareceres e resoluções do Conselho Nacional de Educação (CNE). Daí a importância do estudo dessas interpretações para a avaliação menos imprecisa das receitas da educação e despesas classificáveis de MDE, conforme definida nos artigos 70 e 71 da LDB.

\section{Referências legais, base empírica e procedimentos}

Esta pesquisa foi iniciada em 1998 (DAVIES, 2001b) e procurou obter as normas editadas pelos TCs desde a Lei Federal no. 7.348 (BRASIL, 1985), que regulamentou a Emenda Constitucional Calmon, de 1983, restabelecendo a vinculação de recursos para a educação, eliminada pela Constituição imposta pela ditadura militar em 1967. Tomamos a Lei $n^{0}$. 7.348 como marco inicial porque desde 1967 não havia vincula- 
ção constitucional de recursos (restabelecida apenas para os municípios pela Emenda Constitucional $n^{\circ} .1$, em 1969) e porque ela vigorou integralmente até dezembro de 1996 (quando foi promulgada a LDB) e parcialmente a partir de janeiro de 1997, segundo a interpretação dada pelo Parecer n ${ }^{\circ}$. 26/97 do Conselho Nacional de Educação (1997). Basicamente, esta Lei 7.348 foi importante porque definiu as receitas e despesas vinculadas à MDE, conceito que mereceu uma definição menos elástica do que a permitida pela função orçamentária de 'Educação e Cultura', prevista na Lei Federal nº. 4.320, de 1964 (BRASIL, 1964) que normatiza a elaboração e execução de orçamentos públicos.

Outras referências legislativas que adotamos foram as Emendas Constitucionais $n^{\circ} \mathrm{S} 14$ (BRASIL, 1996a), e 53 (BRASIL, 2006), e as Leis nºs 9.394 (BRASIL, 1996b), 9.424 (BRASIL, 1996c), sendo que esta última regulamentou o Fundo de Manutenção e Desenvolvimento do Ensino Fundamental e de Valorização dos Profissionais do Magistério (Fundef), ambas de dezembro de 1996, e a 11.494 (BRASIL, 2007a), que regulamentou o Fundo de Manutenção e Desenvolvimento da Educação Básica e de Valorização dos Profissionais da Educação (Fundeb).

Também era nosso desejo examinar pareceres concretos dos TCs sobre contas de governos estaduais e municipais, uma vez que a nossa experiência no Estado do Rio de Janeiro revelara a não coincidência de procedimentos recomendados pelos TCs e os efetivamente seguidos pelos seus técnicos e conselheiros.

Basicamente, as informações e documentos que procuramos obter junto aos TCs foram as seguintes:

(1) Legislação federal, estadual ou municipal adotada pelos TCs para a averiguação das receitas e despesas vinculadas à educação ou, mais precisamente, à MDE, conforme definida na Lei ${ }^{\circ}$. 7.348 (BRASIL, 1985), e nos artigos 70 e 71 da LDB (BRASIL, 1996). Queríamos saber, por exemplo, o percentual mínimo que os TCs consideravam correto, no caso de o percentual das Constituições estaduais e leis orgânicas ser superior aos 25\% previstos na Constituição Federal (CF) de 1988 (BRASIL, 1988). Essa nossa indagação foi suscitada pela experiência no Estado do Rio de Janeiro, em que prefeituras (por exemplo, Petrópolis, São Gonçalo) cujas leis orgânicas fixavam um valor superior aos 25\% alegavam que o percentual válido era o da CF, não o das leis orgânicas, e contavam com a interpretação favorável do TCE. Além disso, o governo estadual do Rio de Janeiro (na gestão de Brizola) havia obtido em 1993 liminar do Supremo Tribunal Federal suspendendo a eficácia do percentual mínimo de 35\% fixado na Constituição Estadual de 1989 (RIO DE JANEIRO, 1989), o que significou, na prática, a aceitação dos $25 \%$ pelo TC. 
(2) Instruções e normas internas elaboradas pelos TCs para o cálculo das receitas e despesas vinculadas à MDE desde a Lei nº 7.348 (BRASIL, 1985). Tais instruções são fundamentais porque os governos estaduais e municipais procuram seguir (quando lhes interessam, é claro) os procedimentos nelas contidos, não necessariamente a Constituição Federal, Estadual ou Lei Orgânica ou a legislação educacional.

(3) Definição dos impostos que compõem a base de cálculo do percentual mínimo. Queríamos saber sobretudo se era computada a receita da divida ativa oriunda de impostos (DAI), sua atualização monetária e as multas e juros de mora sobre DAl. Essa questão se deveu ao fato de prefeituras fluminenses não a incluirem e de o TCE não tê-la contabilizado por muitos anos.

(4) No caso do Fundef/Fundeb, contabilização dos ganhos (que ocorrem quando o governo recebe do Fundo mais do que contribui), complementação federal e rendimentos financeiros com o Fundef/Fundeb, receitas do salárioeducação (que é contribuição social, não imposto e, portanto não deve ser incluído nos 25\%), convênios de natureza educacional (merenda e outros), e receitas de serviços prestados por instituições educacionais e operações de crédito para a educação. Eram/são contabilizados como parte do percentual mínimo ou como acréscimos a ele? Este cálculo é importante porque muitas vezes os governos omitem tais receitas ou as incluem na base de cálculo do percentual mínimo, quando o correto é acrescentá-las integralmente ao mínimo, pois não têm origem nos $25 \%$ dos impostos.

(5) Critérios de cálculo do valor devido em educação: valores nominais ou valores reais, ou, em outras palavras, os valores devidos são corrigidos monetariamente?. Estes critérios são fundamentais numa época de inflação alta e mesmo após a decretação do Plano Real, em julho de 1994, porque a inflação persistiu, embora relativamente baixa.

(6) Definição de despesas consideradas como MDE. É fundamental a clareza sobre essa definição porque não raro os governos confundem tais despesas com as realizadas na função orçamentária 'Educação e Cultura', modificada para 'Educação' a partir de 2001, mais ampla do que o conceito de MDE, ou com o órgão responsável pela educação.

(7) Critérios de cálculo das despesas em MDE - valores empenhados, liquidados ou pagos no ano. Essa diferenciação é fundamental porque não era/é incomum os governos considerarem os valores empenhados como os aplicados no ensino, mas cancelarem uma parte de tais empenhos no exercício seguinte, fraudando, assim, os valores aplicados no ensino.

(8) Procedimentos adotados pelos TCs tendo em vista implantação obrigatória do Fundef, em 1998, e do Fundeb, em 2007. 
Entendemos que o procedimento correto deveria especificar:

(1) no mínimo $25 \%$ de todos os impostos mais o ganho (a diferença positiva entre contribuição e receita) com o Fundef, de 1998 a 2006 (ou o Fundeb, desde 2007), mais as demais receitas integralmente vinculadas à educação (operações de crédito para a educação, salário-educação, convênios, programas e demais repasses, sobretudo federais, etc.),

(2) todas as despesas financiáveis apenas com o Fundef (ou o Fundeb),

(3) todas as despesas vinculadas constitucionalmente ao ensino fundamental até 2006 e financiáveis com os 15\% de todos os impostos municipais (IPTU, ISS, ITBI, IR, IPVA, ITR) e estaduais (IPVA, ITCD) que não integravam o Fundef, conforme previsto na EC 14 (BRASIL, 1996).

(4) as demais despesas financiáveis com os 10\% dos impostos não vinculados constitucionalmente ao ensino fundamental até 2006 e com as receitas contabilizáveis fora dos 25\% (convênios, programas, etc.),

(5) as demais despesas financiáveis com os recursos que não integram o Fundeb desde 2007.

\section{O Tribunal de Contas do Estado da Bahia}

Aparentemente, o TC nunca emitiu resolução sobre a receita e despesa vinculada à MDE ou ao Fundef ou Fundeb '. Por isso, a nossa avaliação se baseou nos relatórios e pareceres prévios do TC sobre as contas estaduais de alguns anos (BAHIA, 1996, 1999, 2002, 2003, 2004, 2005, 2007).

Os procedimentos do TC não só variaram ao longo do tempo, como também apresentaram muitos equívocos e dados discrepantes. Muitos dos equívocos teriam sido evitados se o TC tivesse seguido com cautela as orientações e tabelas contidas nos manuais editados pela Secretaria do Tesouro Nacional desde 2001 para a elaboração dos relatórios resumidos da execução orçamentária (RREOs). A recomendação de cautela se justifica porque os manuais destes RREOs também continham equívocos.

Por exemplo, no relatório do TC sobre as contas estaduais de 1996 a divida ativa de impostos, suas multas e juros de mora não foram incluídos na base de cálculo do percentual mínimo, equívoco corrigido no relatório sobre as contas de 1999 e dos anos seguintes examinados.

Um grave equívoco do TC foi não acrescentar ao percentual mínimo as receitas do salário-educação (contribuição social que incide sobre a folha de pagamento das em-

Pelo menos com base nas informações disponiveis no Portal do Tribunal de Contas do Estado da Bahia: <www.tce.ba.gov.br>. Acesso em: set. 2008. 
presas), repasses federais para programas específicos (merenda, Programa Dinheiro Direto na Escola, por exemplo), complementação federal para o Fundef ou rendimentos financeiros com a receita do Fundef ou operações de crédito vinculadas à educação. Em 1999 tais receitas corresponderam a R\$ 27 milhões (convênios do Fundo Nacional de Desenvolvimento da Educação (FNDE)), R\$28,7 milhões (quota-estadual do salárioeducação), R\$ 11 milhões (operações de crédito do Projeto Nordeste), R\$ 82,7 milhões (complementação federal para o Fundef). Tais receitas ou não são mencionadas ou são contabilizadas de maneira equivocada. Por exemplo, o relatório das contas de 1999 incluiu na base de cálculo do percentual mínimo R\$ 117,9 milhões de transferências federais, que provavelmente correspondem a algumas das receitas citadas e deveriam ser acrescentadas ao percentual mínimo e não incluídas na base de cálculo. Também os relatórios sobre as contas de 2002, 2003, 2004, 2005 e 2007 não mencionam tais receitas. 0 relatório sobre as contas de 2003 (BAHIA, 2004, p. 207) informa porém não contabiliza o empréstimo do Banco Mundial para o Projeto Bahia (vinculado à educação) assinado em 2001 prevendo US\$ 116 milhões na primeira fase (encerrada em 30 de junho de 2003) e US\$ 100 milhões na segunda fase (até 2006), sendo 60\% do Banco Mundial e 40\% de contrapartida do Estado. Segundo o relatório sobre as contas de 2004, este projeto teria consumido R\$ 308 milhões de 2001 a 2003, tendo sido a análise de seus documentos prejudicada "porque um incêndio ocorrido na Secretaria de Educação destruiu a totalidade dos documentos" (BAHIA, 2004, p. 209). 0 relatório sobre as contas de 2002 mostra a importância destes recursos com origem em operações de crédito. 0 projeto Bahia teria consumido $\mathrm{R} \$ 162,9$ milhões, o Fundo de Fortalecimento da Escola (Fundescola), financiado pelo Banco Mundial e pelo Ministério da Educação (MEC), R\$ 19 milhões, o Programa de Expansão da Educação Profissional (PROEP), financiado pelo Banco Interamericano de Desenvolvimento (BID), R\$ 6 milhões.

A propósito dos rendimentos financeiros do Fundef, nunca foram incorporados à receita do Fundef porque, segundo os relatórios, o governo estadual não os lançou na conta do Fundef, optando (ilegalmente) por movimentá-los através de uma conta que reúne outras fontes do Tesouro Estadual e, portanto, dificultando "a segregação e o rateio das receitas financeiras individualmente." (BAHIA, 2000, p. 223), e infringindo, assim, a Lei n. 9.424 (BRASIL, 1996c). Esta ilegalidade continuou no primeiro ano de vigência do Fundeb, em 2007, apesar de denunciada pelo TC desde pelo menos as contas de 1999.

A discrepância entre os dados fornecidos pelo governo e os utilizados pelo TC é um dos problemas na análise das contas. Segundo o relatório sobre as contas de 2003 (BAHIA, 2004, p. 63), o total de impostos apurado pelo TC para cálculo do percentual mínimo - $\mathrm{R} \$ 6,921$ bilhões - seria $\mathrm{R} \$ 154$ milhões superior à receita indicada no balanço geral do Estado ( $R$ \$ 6,767 bilhões). Isso porque o governo não teria incluído a receita do ICMS adicional, que compõe o Fundo de Combate e Erradicação da Pobreza (FECEP), bem como suas multas e juros de mora. Esta con- 
tabilização divergente entre o TC e o governo aconteceu também nas contas de 2002 e continuou pelo menos em 2007, em que esta diferença entre a receita calculada pelo TC e a apurada pelo governo teria aumentado para $\mathrm{R} \$ 266$ milhões. Às vezes, as discrepâncias são encontradas no mesmo relatório do TC. Por exemplo, segundo o relatório sobre as contas de 2003, a despesa na função Educação teria sido de $R \$ 1,615$ bilhão, ao passo que o dispêndio em MDE teria sido de $R \$ 1,863$ bilhão (BAHIA, 2004, p. 63). Já o relatório sobre as contas de 2004 afirma que 0 Estado aplicou em MDE (considerada equivocadamente de função Educação) $R$ \$ 1.185.107.704, montante que seria de $R \$ 2,245$ bilhões (BAHIA, 2005a, p. 45-46). Outra discrepância é registrada nesse relatório sobre as contas de 2004, segundo a qual a execução orçamentária na função Educação teria sido de $R$ \$ 1.731.897.973 (BAHIA, 2005a, p. 183). As discrepâncias constam também do relatório sobre as contas de 2005, informando que os gastos em MDE foram de $R$ \$ 2.597.241.664, porém mais adiante, fornece outro dado sobre a execução orçamentária na função Educação: $R$ \$ 2.045.756.232 (BAHIA, 2006a, p. 55, 205). 0 relatório sobre as contas de 2007 (BAHIA, 2008), por sua vez, informa, na tabela 5, que o governo estadual perdeu $\mathrm{R} \$ 948,600$ milhões com o Fundeb, porém a tabela 8 informa que as perdas foram de $R \$ 816,753$ milhões.

Outra falha do TC é não definir com precisão o que entende por MDE, quase sempre confundido com a função Educação e Cultura (vigente antes de 2001) ou Educação (em vigor a partir de 2001). Ora, MDE é um conceito definido pelos artigos 70 e 71 da LDB (BRASIL, 1996b), enquanto a função Educação é definida pela Lei no. 4.320 (BRASIL, 1964), que dispõe sobre orçamento público. A falta de atenção do TC para a distinção entre o conceito de MDE e a função Educação e a separação entre as despesas financiadas (1) com os 25\% dos impostos, (2) as do Fundef ou Fundeb, e (3) as pagas com receitas adicionais ao mínimo (salário-educação, convênios, operações de crédito) pode ter levado o TC a cálculos equivocados, contabilizando, dentro dos 25\% dos impostos, dispêndios pagos com as receitas do Fundef/Fundeb (2) ou as adicionais (3) (BRASIL, 2003).

Esta confusão entre MDE e a função Educação aconteceu em vários anos. Em 1999, o TC considerou gastos na função 'Educação e Cultura' (R\$ 1,032 bilhão) mais os efetuados na função 'Assistência e Previdência' ( $R$ \$ 66 milhões) da Secretaria de Educação e no Programa Ensino Fundamental ( $R$ \$ 29.107) da Secretaria de Segurança Pública o mesmo que gastos em MDE. 0 prejuízo causado por essa confusão foi atenuado pela dedução, do total despendido na função 'Educação e Cultura', dos gastos nos programas de educação física e desportos ( $R$ \$ 5,29 milhões) e cultura ( $R$ \$ 54,79 milhões). Em 2003 as despesas em MDE (R\$ 1,863 bilhão - p. 63) são diferentes das realizadas na função/subfunção Educação $(R \$ 1,615$ bilhão - $p$. 63), porém o TC não especifica as despesas englobadas em MDE. Se tivesse feito isso, provavelmente muitas despesas teriam sido excluídas da categoria de MDE, 
como merenda e inativos. Em 1996, por exemplo, o TC aceitou que R 125 milhões gastos com os inativos fossem contabilizados no cálculo das despesas de MDE. É possivel que este equívoco tenha continuado até hoje.

Outra deficiência dos relatórios do TC é não demonstrar preocupação com 0 controle de restos a pagar inscritos em exercícios anteriores, ou informar se as despesas são empenhadas, liquidadas ou pagas, conforme recomendado pela STN em seus manuais. Esta é uma questão crucial porque os empenhos podem ser cancelados e, portanto, não resultam necessariamente em liquidação e pagamento.

Apesar de ter cometido muitos equívocos, o TC merece ser elogiado por denunciar em vários relatórios um problema recorrente na administração estadual, que tem sido a contratação temporária de funcionários em vez da realização de concurso público. Em 2007, por exemplo, para um total de 143.508 ativos, 33.239 (ou 23,16\%) eram contratados temporários pelo Reda (Regime Especial de Direito Administrativo), correspondentes a 3,41\% dos gastos totais com pessoal. Ou seja, o governo gastou $(3,41 \%)$ com os contratados $(23,16 \%$ do total de servidores) proporcionalmente muito menos do que com os concursados (96,59\%). Muito provavelmente isso explica porque esta prática ilegal e inconstitucional, apontada nos relatórios do TC, prosseguiu até hoje, além de tender a favorecer o clientelismo, conforme denuncia o conselheiro Filemon Matos no relatório sobre as contas de 2002. No caso da educação, a proporção dos contratados tem sido significativa, sendo de 19.286 em 2007, correspondendo a um dispêndio de $R$ \$ 106 milhões. Supondo-se que estes 19.286 contratados trabalharam 12 meses em 2007, terão sido remunerados em cerca de pouco mais ou menos do que $R \$ 400$, isso no primeiro ano de implantação do Fundeb, o Fundo que, segundo o discurso oficial ou dos com ele identificados, iria valorizar o magistério.

\section{Tribunal de Contas dos Municípios da Bahia (TCM)}

Os comentários a seguir se baseiam nas resoluções do TCM citadas na bibliografia. Antes de comentá-las, vale ressaltar um ponto positivo no Portal do TCM², que é informar as contas aprovadas, aprovadas com ressalvas ou rejeitadas de todos os municípios desde 1993.

Uma primeira observação que cabe fazer é que as resoluções não seguem fielmente as determinações contidas na CF (BRASIL, 1988), na LDB (BRASIL, 1996b) ou no Parecer 26/97 (CONSELHO NACIONAL DE EDUCAÇÃO, 1997), que interpreta as disposições sobre o financiamento da educação na LDB. Tampouco obedecem-se às orientações da Secretaria do Tesouro Nacional oferecidas, a partir de 2001, em manuais (BRASIL, 2003) para a elaboração dos Relatórios Resumidos da Execução

${ }^{2}$ Disponivel em: < www.tcm.ba.gov.br >. Acesso em: 26 fev. 2010. 
Orçamentária (RREOs), que contêm tabelas bastante detalhadas. Em suma, as resoluções do TCM são elaboradas sem nenhum critério claro ou referência na legislação pertinente. Se fossem acompanhadas de tabelas, provavelmente algumas dúvidas poderiam ter sido sanadas.

Uma segunda observação é que algumas resoluções, como a nº 354 (BAHIA, 1998), contêm artigos idênticos à Resolução no 1.606 (PIAUÍ, 1998). Um exemplo é o inciso $V$ do art. $5^{\circ}$ da 354, idêntico ao inciso $V$ do art. $3^{\circ}$ da 1.606 do TC do Piaui: "realização de atividades-meio necessárias ao funcionamento dos sistemas de ensino, incluídas as desempenhadas por pessoal de apoio administrativo, vigilantes, zelador, motoristas de transporte vinculado ao ensino, bibliotecários, jardineiros e secretários de escola". Outra cópia é o inciso IV do art. $5^{\circ}$ da Resolução $n^{\circ}$. 354, segundo o qual "levantamentos estatísticos, estudos e pesquisas, visando precipuamente ao aprimoramento da qualidade e expansão do ensino, a exemplo da apuração dos índices de evasão, aproveitamento e repetência escolares" são despesas em MDE.

Além de cópias, a resolução contém erros de português e redação pouco clara. 0 art. $2^{\circ}$ da 354 estipula que "os Municípios encaminharão, junto à sua documentação mensal", quando o certo é "junto com". 0 § $4^{\circ}$ do Art. 18, por sua vez, referese a 'curso escolar', quando o correto é 'censo escolar'. 0 trecho a seguir tem redação pouco clara: "A despesa resultante de contribuição a maior promovida pelo Município ao Fundo, decorrente dos poucos alunos identificados no curso Escolar, integrará o total do valor aplicado com fim ao cumprimento do artigo 212 da CF."

Os equívocos e redação pouco clara continuaram em resoluções posteriores por exemplo, na $n^{\circ} .396$ (BAHIA, 1999), e na $n^{\circ} .1 .063$ (BAHIA, 2005c). A redação às vezes confusa aparece em outros trechos, como no seguinte: "A receita municipal proveniente das retenções efetuadas a título de ISS e IRRF sobre despesas realizadas na aplicação dos recursos do FUNDEF não incorporarão os valores do FUNDEF, devendo ser apropriadas pelo município." (BAHIA, 1998, art. 3ㅇ, § 4).

Além disso, as resoluções contêm muitos equivocos, indicados a seguir. 0 principal é não definir de maneira clara as receitas vinculadas à educação, conforme explicado acima. Esta deficiência poderia ter sido sanada se as resoluções fossem acompanhadas de tabelas especificando as receitas e despesas vinculadas à MDE.

Um exemplo de falta de clareza é a Resolução nº 354 (BAHIA, 1998), por exemplo, alterada pela no. 396 (BAHIA, 1999) e também pela no. 1.063 (BAHIA, 2005c), que pretendeu regulamentar o Fundef (pelo menos é o que consta de sua ementa), mas se referiu também aos impostos não incluídos no Fundef, como os 25\% do IPTU, ISS, ITBI e IR dos servidores municipais, bem como os 10\% do ICMS, FPM, IPI-exportação e compensação financeira prevista na Lei Complementar 87/96 (co- 
nhecida como Lei Kandir, de desoneração do ICMS das exportações). 0 mesmo equívoco foi cometido pela Resolução n. 1.251 (BAHIA, 2007a), que pretendeu regulamentar o Fundeb (é o que consta de sua ementa) mas se referiu também a recursos não incluídos no Fundeb porém vinculados à MDE.

0 equívoco da Resolução nº 354 (BAHIA, 1998) fica evidente no título do art. $1^{\circ}$, que se refere à constituição do Fundef, composto na verdade por apenas $15 \%$ de alguns impostos, porém o texto do art. se refere aos 25\%. A propósito, na definição dos impostos que os municípios contribuem para o Fundef, a n ${ }^{\circ}$. 354, assim como a $n^{\circ}$. 396, que a alterou, se equivocaram ao omitir o IPI-exportação. Nenhuma resolução tampouco menciona a divida ativa de impostos como componente da base de cálculo do percentual mínimo. Entretanto, corretamente as Resoluções 354, 396 e 1.063 deixam claro que recursos adicionais ao mínimo (convênios e programas com destinação específica) não fazem parte dos 25\% (BAHIA, 1998, art. 8). Sobre isso a Resolução nº 1.251 (BAHIA, 2007a) foi omissa.

Outros equívocos constam da Resolução nº 648 (BAHIA, 2002), que enumera irregularidades e falhas que poderão motivar a rejeição de contas municipais. Um é estipular que a irregularidade consiste em não aplicar pelo menos 25\% da receita tributária municipal, quando o certo é a receita de impostos (que não é o mesmo que receita tributária) mais todas as demais receitas adicionais vinculadas à educação. Outro equívoco foi determinar que o percentual mínimo deve ser aplicado na pré-escola e no ensino fundamental, quando o certo é na educação infantil e no ensino fundamental.

Na definição das despesas em MDE, também são muitos os equívocos, a começar pela terminologia. 0 item d) do art. $3^{\circ}$ da 354 (BAHIA, 1998) solicita demonstrativo das despesas no ensino básico e fundamental, quando provavelmente pretendia dizer "educação infantil" no lugar de "ensino básico", o qual, pela LDB (que emprega a expressão "educação básica"), abrange desde a educação infantil até o ensino médio. Além disso, contradiz 0 art. $2^{\circ}$, que solicita aos municípios encaminharem documentos relativos à aplicação no ensino fundamental, quando o certo seria no ensino apenas. Ao prever que os "os Municípios atuarão, prioritariamente, no ensino fundamental e pré-escolar", a resolução 354 comete outro equívoco no parágrafo único do seu art. $4^{\circ}$, pois sua atuação prioritária é no ensino fundamental e na educação infantil, conforme prevê a Emenda Constitucional 14.

A falta de clareza das resoluções fez com que elas confundissem despesas no ensino, despesas no ensino fundamental e despesas no Fundef. Ora, as despesas no ensino (financiadas com no mínimo 25\% de todos os impostos, ganho com o Fundef e receitas adicionais aos 25\%) são muito mais amplas, pois abrangem todas as demais. As do ensino fundamental, por sua vez, se destinavam a identificar apenas as financiáveis com os 15\% dos impostos (IPTU, ISS, ITBI, IR dos servidores municipais, IPVA, ITR) vincula- 
dos ao ensino fundamental municipal até 2006 e não integrantes do Fundef. Já as do Fundef, embora vinculadas também ao ensino fundamental, são formadas pela receita da prefeitura com o Fundef, seu rendimento financeiro e complementação federal. Em síntese, são três as categorias de despesas, uma abrangente e duas específicas. Esta falta de clareza fica evidente nas três resoluções (354, de 1998, 396, de 1999, e 1.063, de 2005), que pretenderam regulamentar o Fundef e definir as despesas financiáveis por ele, mas utilizam ora a terminologia de MDE (354), ora a de manutenção e desenvolvimento no ensino fundamental (BAHIA, 1999, 2005c), conferindo a esta terminologia um sentido não previsto nos artigos 70 e 71 da LDB. A propósito dos gastos no ensino fundamental, as Resoluções 396 e 1.063 prevêem, no seu inciso III e também em outros, uma classificação impossivel de operacionalizar, que é a "aquisição, manutenção, construção e conservação de instalações e equipamentos, inclusive quadras poliesportivas, bibliotecas e teatros anexos à unidade educacional". Ora, tais instalações e equipamentos são destinados à educação como um todo, nunca apenas ao ensino fundamental.

Outro equívoco - copiado da Resolução 1.606 (PIAUÍ, 1998) - das resoluções (inclusive a do Fundeb) foi considerar como MDE os recursos destinados a escolas comunitárias, confessionais ou filantrópicas, desde que atendessem às condições previstas no art. 77, incisos I a IV da LDB (BRASIL, 1996b). Embora tais escolas possam receber recursos públicos, estes não podem ser classificados como $M D E$, segundo a LDB, nem ser financiados por 25\% dos impostos e demais receitas vinculadas à educação (convênios, salário-educação, etc.). Outra ilegalidade foi aceitar que tais escolas pudessem receber parte dos 40\% dos recursos do Fundef (ou do Fundeb), o qual se destinava/destina exclusivamente ao ensino fundamental público (Fundef) ou à educação básica pública (Fundeb) e, portanto, não poderia beneficiar tais escolas não públicas.

Um equívoco da Resolução 648 (BAHIA, 2002), foi prever que 40\% do Fundef devem ser gastos nas despesas previstas no art. 70 da Lei no. 9.394 (BRASIL, 1996b). Ora, estas últimas abrangem toda a educação, ao passo que o Fundef se destinava apenas ao ensino fundamental público. A destinação equivocada do Fundef também consta de outra resolução, a 1.060 (PIAUÍ, 1998, art. 4º $\$ 3^{\circ}$, alínea a): não específica da educação, que determina que a prefeitura identifique as "realizadas com recursos do Fundef na manutenção e desenvolvimento do ensino público pré-escolar e fundamental". Ora, o Fundef se destinava apenas ao ensino fundamental.

Outro equívoco - copiado da Resolução 1.606 (PIAUÍ, 1998) - é a interpretação sobre o emprego do Fundef em bolsas de estudo em escolas privadas, não previsto na lei do Fundef (BRASIL, 1996c). 0 equívoco está no fato de o Fundef ter-se destinado apenas ao ensino fundamental público e, portanto, não poderia ser empregado em escolas privadas. 0 TC confundiu despesas em MDE (definidas nos artigos 70 e 71 da LDB), que incluem bolsas de estudo em escolas privadas, com despesas no Fundef, que 
só podiam ser no ensino fundamental público. Equívoco semelhante foi cometido pela Resolução 648 (BAHIA, 2002). 0 TCM parece ter percebido este equívoco posteriormente, pois na Resolução n. 1.251 (BAHIA, 2007a) excluiu tais bolsas da categoria de despesas de manutenção e desenvolvimento da educação básica pública.

A propósito da permissão de uso dos recursos do Fundef em escolas comunitárias, confessionais ou filantrópicas ou em bolsas de estudo em escolas privadas, a Resolução 1.063 (BAHIA, 2005c), foi internamente contraditória, pois permitiu este uso mas seu art. $1^{\circ}$ estipulou que o Fundef se destinava ao ensino fundamental público.

Outro equívoco foi utilizar o termo "valorização" como sinônimo de remuneração, algo bem específico, que não resulta necessariamente em valorização, pelo menos no sentido de melhoria salarial. 0 art. $2^{\circ}$ da 354 (BAHIA, 1998) pede que os documentos informem os gastos na valorização do magistério, quando quis dizer 'remuneração'.

Um ponto positivo das resoluções foi não se basear nas despesas empenhadas, mas sim nas pagas no exercício, para efeito de cálculo do percentual mínimo, impedindo ou pelo menos dificultando a manobra contábil dos governos de alegar ter gasto um valor que foi apenas empenhado. Entretanto, ao considerar que as despesas de exercícios anteriores ("os restos a pagar") serão contabilizadas nos exercícios em que forem efetivamente pagas, o TCM distorce o cálculo do percentual aplicado no exercício, pois tais despesas têm origem em receitas de exercícios anteriores. Tais despesas, assim como tais receitas, deveriam ser classificadas numa categoria à parte, extra-orçamentária, pois não fazem parte do orçamento do exercício em questão.

\section{Conclusão}

Os procedimentos adotados pelo TCE e pelo TCM para a verificação da receita e despesa vinculada à educação mostram que cometeram uma série de omissões, inconsistências e equívocos. 0 TCE, por exemplo, se limitou à contabilização do percentual mínimo dos impostos e nunca mencionou as receitas adicionais a este mínimo, como o salário-educação, os repasses federais para merenda e outros programas ou operações de crédito vinculadas à educação, significativas no caso da Bahia. Além disso, os relatórios do TCE contêm dados discrepantes e confundem gastos na função orçamentária Educação com os realizados em manutenção e desenvolvimento do ensino, dois conceitos diferentes. Também o TCM cometeu muitos equívocos em suas resoluções, a começar pela terminologia. Empregou 'ensino básico' no lugar de 'educação infantil' e confundiu despesas no ensino (categoria mais ampla) com despesas no Fundef (categoria mais restrita). Incorreu em ilegalidade ao aceitar que parte dos 40\% dos recursos do Fundef (ou do Fundeb) fossem destinados a escolas comunitárias, confessionais ou filantrópicas. 
A principal implicação disso é que a educação na Bahia perdeu e perde muitos recursos por causa destes equívocos cometidos pelos TCs em suas instruções normativas (quando existem) ou em sua contabilização de receita e despesa, que não seguem necessariamente a legislação pertinente. Isso indica a necessidade de os educadores não se limitarem a analisar a legislação educacional (Constituição Federal, LDB, etc.), verificando também como os governos e os Tribunais contabilizam as receitas e despesas em educação, o que permitiria um maior controle social sobre os recursos da educação.

\section{Referências}

BAHIA. Tribunal de Contas do Estado. Relatório e parecer prévio sobre as contas do Estado da Bahia: Poderes Legislativo, Judiciário e Executivo e Ministério Público: exercício de 1996. Salvador, 1997. Disponível em: <http:// www.tce.ba.gov.br>. Acesso em: set. 2008.

Relatório e parecer prévio sobre as contas do Estado da Bahia: Poderes Legislativo, Judiciário e Executivo e Ministério Público: exercício de 1999. Salvador, 2000. Disponivel em: <http://www.tce.ba.gov.br>. Acesso em: set. 2008.

Relatório e parecer prévio sobre as contas do Estado da Bahia: Poderes Legislativo, Judiciário e Executivo e Ministério Público: exercício de 2002. Salvador, 2003. Disponivel em: <http://www.tce.ba.gov.br>. Acesso em: set. 2008.

Relatório e parecer prévio sobre as contas do Estado da Bahia:

Poderes Legislativo, Judiciário e Executivo e Ministério Público: exercício de 2003. Salvador, 2004. Disponivel em: <http://www.tce.ba.gov.br>. Acesso em: set. 2008.

Relatório e parecer prévio sobre as contas do Estado da Bahia: Poderes Legislativo, Judiciário e Executivo e Ministério Público: exercício de 2004. Salvador, 2005a. Disponivel em: <http://www.tce.ba.gov.br>. Acesso em: set. 2008.

Relatório e parecer prévio sobre as contas do Estado da Bahia: Poderes Legislativo, Judiciário e Executivo e Ministério Público: exercício de 2005. Salvador, 2006a. Disponível em: <http://www.tce.ba.gov.br>. Acesso em: set. 2008.

Relatório e parecer prévio sobre as contas do Estado da Bahia: Poderes Legislativo, Judiciário e Executivo e Ministério Público: exercício de 2007. Salvador, 2008. Disponivel em: <http://www.tce.ba.gov.br>. Acesso em: set. 2008. 
BAHIA. Tribunal de Contas dos Municípios. Resolução n. 354, de 17 de dezembro de 1998. Estabelece procedimentos e instrui os gestores municipais quanto ao funcionamento do Fundo de Manutenção e Desenvolvimento do Ensino Fundamental e de Valorização do Magistério - Fundef - no âmbito dos municipios. Revista do Tribunal de Contas dos Municípios do Estado da Bahia. Salvador, Ano 2, n. 3, 1998. Alterada pelas Resoluções TCM n 396/99, de 29/12/ 99, e 428/2000, de 15/03/2000.

. Resolução nº. 396, de 29 de dezembro de 1999. Dá nova redação a dispositivos da Resolução n. 354/98, que estabelece procedimentos e instrui os gestores municipais quanto ao funcionamento do FUNDEF no âmbito dos municípios e dá outras providências. Resolução, Salvador, 1999. Disponível em: <http://www.tcm.ba.gov.br> Acesso em: set. 2008.

. Resolução n. 648, de 19 de dezembro de 2002. Enumera irregularidades e falhas que poderão motivar a rejeição de contas municipais. Resolução, Salvador, 2002. Disponivel em: <http://www.tcm.ba.gov.br> Acesso em: set. 2008.

. Resolução $n^{\circ}$. 1.060, de 26 de abril de 2005. Estabelece normas para a apresentação da documentação mensal da receita e despesa e da prestação de contas anual de Prefeituras e Mesas de Câmaras, revoga a Resolução TCM n. 220/92, e dá outras providências. Resolução, Salvador, 2005b. Disponível em: $<$ http://www.tcm.ba.gov.br> Acesso: em set. 2008.

. Resolução nº 1.063, de 18 de maio de 2005. Disciplina a aplicação, pelos municípios, dos recursos do FUNDEF e dá outras providências. Resolução, Salvador, 2005c. Disponivel em: <http://www.tcm.ba.gov.br>. Acesso: em set. 2008.

Resolução nº. 1.195, de 30 de março de 2006. Dá nova redação ao art. $6^{\circ}$, § $1^{\circ}$, e art. $8^{\circ}$ da Resolução n. 1063/05; ao art. 11 da Resolução nº. 1064/05, e dá outras providências. Resolução, Salvador, 2006b. Disponivel em: <http:// www.tcm.ba.gov.br>. Acesso em: set. 2008.

Resolução n. 1251, de 29 de março de 2007. Regulamenta a implantação, nos municípios baianos, do Fundo de Manutenção e Desenvolvimento da Educação Básica e de Valorização dos Profissionais da Educação - FUNDEB, dispõe sobre a aplicação de seus recursos, e dá outras providências. Resolução, Salvador, 2007a. Disponivel em: <http:// www.tcm.ba.gov.br>. Acesso em: set. 2008. 
BAHIA. Tribunal de Contas dos Municípios. Resolução n. 1.256, de 25de julho de 2007. Altera dispositivos da Resolução TCM n. 1.251/07, que regulamenta a implantação, nos municípios baianos, do FUNDEB, e dá outras providências. Resolução, Salvador, 2007b. Disponivel em: <http://www.tcm.ba.gov.br>. Acesso em: set. 2008.

BRASIL. Constituição (1988). Constituição da República Federativa do Brasil. Brasilia, DF, 1988. Disponivel em: <http://www.senado.gov.br>. Acesso em: fev. 2008.

. Emenda Constitucional $n^{\circ} .14$, de 12 de setembro de 1996. Modifica os arts. 34, 208, 211 e 212 da Constituição Federal e dá nova redação ao art. 60 do Ato das Disposições constitucionais Transitórias. Diário Oficial da União, Brasília, DF, 13 set. 1996a. Disponivel em: < www.planalto.gov.br/ccivil.../Emendas/.../emc14.htm >. Acesso em: out. 2005.

Emenda Constitucional $n^{\circ} .53$, de 19 de dezembro de 2006. Dá nova redação aos arts. 7 , 23, 30, 206, 208, 211 e 212 da Constituição Federal e ao art. 60 do Ato das Disposições Constitucionais Transitórias. Brasilia, 2006. Diário Oficial da União, Brasilia, DF, 9 mar. 2006. Disponivel em: <http:// www.planalto.gov.br> Acesso em: jan. 2007.

. Lei nº. 4.320, de 17 de março de 1964. Estatui Normas Gerais de Direito Financeiro para elaboração e contrôle dos orçamentos e balanços da União, dos Estados, dos Municípios e do Distrito Federal. Diário Oficial da União, Brasília, DF, 23 mar. 1964. Disponivel em: <http://www.planalto.gov.br/ccivil_03/Leis/ L4320.htm>. Acesso em: 25 fev. 2010.

. Lei $n^{\circ} .11 .494$, de 20 de junho de 2007. Regulamenta o Fundo de Manutenção e Desenvolvimento da Educação Básica e de Valorização dos Profissionais da Educação - FUNDEB, de que trata o art. 60 do Ato das Disposições Constitucionais Transitórias; altera a Lei $n^{0} 10.195$, de 14 de fevereiro de 2001; revoga dispositivos das Leis ${ }^{0 s} 9.424$, de 24 de dezembro de 1996, 10.880, de 9 de junho de 2004, e 10.845, de 5 de março de 2004; e dá outras providências. Diário Oficial da União, Brasília, DF, 21 jun. 2007a. Disponivel em: $<$ http://www.planalto.gov.br> Acesso em: jul. 2007.

. Lei $n^{\circ}$. 7.348, de 24 de julho de 1985. Dispõe sobre a execução do $\S 4^{\circ}$ do art. 176 da Constituição Federal e dá outras providências. Diário Oficial da União, Brasilia, DF, 24 jul. 1985. Disponivel em: < http://www.soleis.adv.br/ emendacalmon.htm>. Acesso em: out. 2005. 
BRASIL. Lei no. 9.394, de 20 de dezembro de 1996. Estabelece as diretrizes e bases da educação nacional. Brasília: Presidência da República. Diário Oficial da União, Brasilia, DF, 23 dez. 1996b. Disponível em: <www.planalto.gov.br>. Acesso em out. 2005.

Lei $n^{\circ}$. 9.424, de 24 de dezembro de 1996. Dispõe sobre o Fundef e dá outras providências. Diário Oficial da União, Brasilia, DF, 26 dez. 1996c. Disponivel em: <www.planalto.gov.br>. Acesso em out. 2005.

. Ministério da Fazenda. Secretaria do Tesouro Nacional. Anexo de metas fiscais e relatório resumido da execução orçamentária: manual de elaboração: aplicado à União e aos Estados, Distrito Federal e Municípios. 7. ed. atual. Brasília, DF: STN, Coordenação-Geral de Contabilidade, 2007b. Disponível em: <http://www.stn.gov.br/legislacao/download/contabilidade/ManualRRE07.pdf >. Acesso em: 1 mar. 2010.

Ministério da Fazenda. Secretaria do Tesouro Nacional. Coordenação Geral de Contabilidade. 3. ed. Relatório resumido da execução orçamentária: manual de elaboração. Brasilia, DF, 2003. Disponivel em:

$<$ http://siops.datasus.gov.br/Documentacao/Portaria\%20441\%20-020manual.pdf >. Acesso em: 26 fev. 2010.

CALLEGARI, C. As verbas da educação: a luta contra a sonegação de recursos do ensino público no Estado de São Paulo. São Paulo: Ed. Entrelinhas, 1997.

CONSELHO NACIONAL DE EDUCAÇÃO (Brasil). Parecer nº. CP 26/97, de 2 de dezembro de 1997. Interpreta o financiamento da educação na LDB. Diário Oficial da União, Brasília, DF, p. 40, 18 dez. 1997. Disponível em: <http://portal.mec.gov.br/cne/arquivos/pdf/PNCP2697.pdf>. Acesso em: jun. 1998.

DAVIES, N. Tribunais de Contas e educação: quem controla o fiscalizador dos recursos?. Brasilia, DF: Ed. Plano, 2001a.

. Tribunal de Contas: faz as contas ou "faz de conta" na avaliação dos gastos governamentais em educação. Revista Brasileira de Estudos Pedagógicos, Brasília, DF, v. 80, n. 194, jan./abr. 1999.

Verbas da educação: o legal x o real. Niterói, RJ: EdUFF, 2000.

PIAUIi. Resolução n. 1.606, de 18 de junho de 1998. Dispõe sobre a fiscalização exercida pelo Tribunal de Contas do Estado sobre a aplicação dos recursos constitucionalmente vinculados à manutenção e desenvolvimento do ensino no Estado do Piauí. Diário da Justiça do Estado do Piauí, Teresina, n. 3.841, 23 jun. 1998. Disponivel em: <http://www.tce.pi.gov.br>. Acesso em: jan. 2008. 
RIO DE JANEIRO. (Estado). Constituição (1989). Constituição do Estado do Rio de Janeiro de 1989. Rio de Janeiro, 5 out. 1989. Disponível em: <http:// www.cmresende.rj.gov.br/PDF/const_est_rj.pdf>. Acesso em: 26 fev. 2010.

Recebido em: 14/08/2009

Aceito em para publicação em: 23/09/2009 